\title{
Success Rate of Intra Cytoplasm Sperm Injection (ICSI) among Sudanese Women with Low Serum Anti-mullerian Hormone (AMH)
}

\author{
Malaz Bashir Alemam ${ }^{1}$, Mohammed Rida ${ }^{2}$, AbdElkarim A. Abdrabo ${ }^{1 *}$ \\ ${ }^{1}$ Department of Clinical Chemistry, Faculty of Medical Laboratory Science, Al-Neelain University, \\ Khartoum-Sudan. \\ ${ }^{2}$ Dr.Elsir Abu-Elhassan Fertlity Center, Khartoum-Sudan. \\ *abdrabokarim@gmail.com
}

\begin{abstract}
Background: A lower level of Anti-mullerian Hormone (AHM) is associated with reduced ovarian reserve and reduced chance of pregnancy with IVF treatments. Previous reports indicated that AMH should not be used as the criteria to exclude couples from performing additional IVF treatments.

Aim: The aim of the current study was to assess the outcome of IVF/ICSI in women with low circulating AMH level $(<1.3 \mathrm{ng} / \mathrm{ml})$ and to examine the difference in IVF/ICSI outcome between women with low serum AMH $(0.2-1.3 \mathrm{ng} / \mathrm{ml})$ and extremely low serum AMH $(<0.2 \mathrm{ng} / \mathrm{ml})$.

Materials and methods: All patients who underwent an IVF/ICSI treatments with FSH stimulation in DR.Elsir Abu-Elhassan Fertility Center between 2016 and 2017 were between 20 to 49 years of age and had low serum AMH level $(<1.3 \mathrm{ng} / \mathrm{ml})$. In total 63 patients were analyzed cross-sectional retrospectively. Statistical analysis was performed with SPSS.

Results: All women underwent IVF/ICSI treatment, the success rate was 20.6\% (13 women), among all women understudy serum FSH was significantly affected the success rate (p-value $<0.05$ ) women with high serum FSH tend to get not success ICSI.There was a low probability to get success ICSI in women with extremely low AMH $(<0.2 \mathrm{ng} / \mathrm{ml})$ compared to women with low AMH $(0.2-1.3 \mathrm{ng} / \mathrm{ml})$, in women with extremely low AMH there was a lower number of oocytes retrieved, a lower number of fertilized oocytes and a lower number of transferred embryos .
\end{abstract}

Conclusion: AMH remains a good quantitative marker of the ovarian reserve but is a poor qualitative marker. Women with low $(<1.3 \mathrm{ng} / \mathrm{ml})$ AMH levels undergoing IVF/ICSI treatments still have reasonable chances of achieving a pregnancy.

\section{INTRODUCTION}

There are numerous markers of ovarian reserve, which are used to prognosticate the chances of success with assisted reproductive techniques (ART), namely, serum follicle-stimulating hormone, estradiol, inhibin B, antimullerian hormone (AMH), biophysical tests such as ovarian volume and peak stromal blood flow velocity and antral follicle count (AFC); all the markers apart from the AFC provide an indirect measurement of the antral follicles, which are the resting pool of the follicles ready to be recruited (1).

According to numerous studies, AMH could predict ovarian response better than $\operatorname{AFC}(2,3)$ and it is a more sensitive probe to identify early follicles not visualized by transvaginal ultrasound (4). 
Success Rate of Intra Cytoplasm Sperm Injection (ICSI) among Sudanese Women with Low Serum Anti-mullerian Hormone (AMH)

$\mathrm{AMH}$, a glycoprotein of the transforming growth factor - B (TGF - B), is produced by granulosa cells of small and large preantral and small antral follicles (5). AMH levels peak at 25 years of age, gradually declining thereafter and reaching undetectable levels a few years before menopause (6-8). AMH is secreted during the early follicular stage by follicles up to $6 \mathrm{~mm}$ in size, is relatively gonadotropin-independent, and remain relatively constant within and between menstrual cycles (9-13).

Since the number of ovarian follicles declines with increasing age, AMH levels might be used as a marker for ovarian aging (14). Human female serum contains measurable amounts of AMH during the reproductive lifespan. (14)Since AMH is solely produced in the growing ovarian follicles, serum levels may be used as a marker for ovarian reserve, representing the quantity and quality of the ovarian follicle pool (14).

Women with serum AMH below the 10th percentile of the general population have been reported to have an overall low global chance of achieving a viable pregnancy (15), and some authors suggested $0.15-0.2 \mathrm{ng} / \mathrm{ml}$ as the AMH cutoff value below which a clinical pregnancy may rarely be obtained after in vitro fertilization (IVF) $(4,16)$. Differently, other studies described ongoing pregnancies after IVF even in patients with low $(17,18)$ or extremely low AMH levels $(<0.1 \mathrm{ng} / \mathrm{ml})$ (19), also including patients older than 40 (20). Obviously, these somehow different results make it difficult to consider circulating AMH as the sole discriminant between women who should be offered IVF treatment and those who should be discouraged.

The current study was designed to determine the success rate of pregnancy in women who have a low AMH level (less than $1.3 \mathrm{ng} / \mathrm{ml}$ ) undergoing assisted reproduction techniques (ART) IVF - ICSI.

\section{Materials AND Methods}

\section{Ethics Statement}

An ethics approval was obtained from Dr.Elsir Abu-Elhassan Fertility Center. For this retrospective study to be carried out using existing patient data in an anonymous manner. The project did not involve any additional intervention or modification from the standard treatment.

\section{Study Population}

This retrospective cross-sectional study carried out using existing patient data in an anonymous manner, the study population comprised 63 women who underwent their in vitro fertilization (IVF)/ intracytoplasmic sperm injection (ICSI) treatment at the Dr.Elsir Abu-Elhassan Center of Fertility, between October 2016 to December 2017.

\section{Inclusion and Exclusion Criteria}

The women under study were between (20-49) years of age, with low serum AMH levels $(<1.3 \mathrm{ng} / \mathrm{ml})$, they previously diagnosed as tubal abnormalities (15.9\%), sperm abnormalities \{male factor\} (33.3\%), tubal abnormalities with sperm abnormalities (14.3), and hypogonadotropic hypogonadism (3.2\%).

None of the women had received hormonal therapy in the previous 3 months. Women with an ovarian cyst $>3$ $\mathrm{cm}$ in diameter), PCOS, endometriosis, a history of ovarian surgery or endocrine disorders were excluded from entering the study.

\section{Hormonal Measurement}

During the follicular phase of the menstrual cycle and prior to treatment, blood samples for assay of AMH, FSH, and luteinizing hormone ( $\mathrm{LH}$ ) were collected by venipuncture. The serum was separated and frozen in aliquots 
Success Rate of Intra Cytoplasm Sperm Injection (ICSI) among Sudanese Women with Low Serum Anti-mullerian Hormone (AMH)

at -80 C for future analysis with the measurement being performed by enzyme-linked immunosorbent assay (ELISA) according to the manufacturer's instructions.

\section{Statistical Analysis}

Data were analyzed using Statistical Program for Social Sciences (SPSS) version 21 the results were expressed as mean, SD, frequency and percentage(\%). The statistic tests used in this study were paired test, Pearson correlation, P-value $<0.005$ considered significant correlation, one sample, and Chi-squared test.

\section{RESULTS}

Table (3-1) show the age group of the women in the study; 20 women (31.7\%) were between 20 - 34 years and 43 women $(68.3 \%)$ were between 35 - 49 years. Table (3-2) show that the study group was divided into two subgroups according to the type of infertility. Women never had been pregnant previously were considered had primary infertility whereas women had been pregnant previously were considered had secondary infertility, 48 women ( $76 \%$ ) had primary infertility while 15 women $(24 \%)$ had secondary infertility.

Table (3-3) show the success rate of the ICSI was underwent to the women in the present study; ICSI treatment succeeded in 13 women(20.6\%) but did not succeed in 50 women $(79.4 \%)$.

Table (3-4) explain the comparison between the mean of study parameters with the mean of the reference values, there was a statistically significant difference $(\mathrm{P}<0.05)$ in the mean concentration of both FSH and LH compared with the mean of their reference value. LH was significantly lower than the reference value but FSH was significantly higher than the reference value.

Table(3-1). age group

\begin{tabular}{|l|c|c|}
\hline Age & Frequency & Percentage (\%) \\
\hline 20-34 Years & 20 & 31.7 \\
\hline 35-49 Years & 43 & 68.3 \\
\hline Total & 63 & 100.0 \\
\hline
\end{tabular}

Table (3-2). Type of infertility

\begin{tabular}{|l|c|c|}
\hline Type & Frequency & Percentage (\%) \\
\hline Primary & 48 & 76.0 \\
\hline Secondary & 15 & 24.0 \\
\hline Total & 63 & 100.0 \\
\hline
\end{tabular}

Table (3-3). comparison between the mean of study parameters with the mean of the reference values:

\begin{tabular}{|l|c|c|c|}
\hline \multicolumn{1}{|c|}{ Parameters } & Mean \pm SD & Mean (R.V) & P-value \\
\hline FSH (mIU/L) & $9.93 \pm 5.19$ & $7.75(4.5-11)$ & 0.001 \\
\hline LH (mIU/L) & $5.51 \pm 2.45$ & $7.8(1.7-13.9)$ & 0.000 \\
\hline LH/FSH ratio & $0.68 \pm 0.44$ & & \\
\hline
\end{tabular}


Success Rate of Intra Cytoplasm Sperm Injection (ICSI) among Sudanese Women with Low Serum Anti-mullerian Hormone (AMH)

Table(3-4). frequency and percentages of the Success and failure rate of the ICSI:

\begin{tabular}{|l|c|c|}
\hline ICSI & Frequency & Percentage (\%) \\
\hline Success & 13 & 20.6 \\
\hline Failed & 50 & 79.4 \\
\hline Total & 63 & 100.0 \\
\hline
\end{tabular}

Table (3-5) show that in present study 21 of patients(33.3\%) had male factor ,10 of patients(15.9\%) had tube damage , 9 of patients(14.3\%) had male factor\& low AMH, 7 patients(11.1\%) had tube damage\& low AMH, 2 of patients(3.2\%) had hypogonadotropic hypogonadism, 9 of patients(14.3\%) had male factor\& tube damage, while 5 of patients(7.9\%) had low AMH .

Table (3-6) shows a significant difference $(\mathrm{P}<0.05)$ between ICSI Success and ICSI not Success as regard FSH but no significant difference $(\mathrm{P}>0.05)$ between ICSI Success and ICSI not Success as regard LH, LH/FSH ratio and $\mathrm{AMH}$.

Table (3-7) explain the distribution of ICSI Success and ICSI, not Success according to AMH groups, the women were divided into two groups according to their AMH levels including women with extremely low AMH levels $(<0.2 \mathrm{ng} / \mathrm{ml})$ and women with low AMH levels $(0.2-1 \mathrm{ng} / \mathrm{ml})$, there were 11 women with Extremely low AMH levels $(<0.2 \mathrm{ng} / \mathrm{ml})\{(4.8 \%)$ gave positive ICSI $\& 12.7 \%$ gave negative ICSI $\}$ and 52 women with low AMH level $(0.2-1 \mathrm{ng} / \mathrm{ml})\{15.9 \%$ gave positive ICSI and $66.7 \%$ gave negative ICSI $\}$, the odds ratio $(>1)$ indicate there was low probability to get success ICSI in women with extremely low AMH than women with low AMH.

Table (3-8) show no significant difference $(\mathrm{P}>0.005)$ between Primary infertility and secondary infertility as regard FSH, LH, LH/FSH ratio and AMH.

Table (3-5). indication for ICSI:

\begin{tabular}{|l|c|c|}
\hline Diagnosis & Frequency & Percentage (\%) \\
\hline Male Factor & 21 & 33.3 \\
\hline Male Factor \& Low AMH & 9 & 14.3 \\
\hline Tube damage & 10 & 15.9 \\
\hline Tube damage \& Low AMH & 7 & 11.1 \\
\hline Hypogonadotropic hypogonadism & 2 & 3.2 \\
\hline Male factor and Tube damage & 9 & 14.3 \\
\hline Low AMH & 5 & 7.9 \\
\hline Total & 63 & 100.0 \\
\hline
\end{tabular}

Table (3-6). Comparison between ICSI Success and ICSI not Success as regard FSH, LH, LH/FSH ratio and AMH:

\begin{tabular}{|l|c|c|c|}
\hline \multicolumn{1}{|c|}{ Parameters } & ICSI Success (Mean \pm SD) & ICSI not Success (Mean \pm SD) & P-value \\
\hline FSH (mIU/L) & $8.98 \pm 3.29$ & $10.18 \pm 3.58$ & 0.023 \\
\hline LH (mIU/L) & $5.86 \pm 3.09$ & $5.42 \pm 2.28$ & 0.568 \\
\hline LH/FSH ratio & $0.79 \pm 0.56$ & $0.65 \pm 0.40$ & 0.304 \\
\hline AMH (ng/mL) & $0.64 \pm 0.37$ & $0.62 \pm 0.37$ & 0.847 \\
\hline
\end{tabular}


Success Rate of Intra Cytoplasm Sperm Injection (ICSI) among Sudanese Women with Low Serum Anti-mullerian Hormone (AMH)

Table (3-7). Distribution of ICSI Success and ICSI not Success according to AMH levels:

\begin{tabular}{|l|c|c|}
\hline \multirow{2}{*}{ AMH group } & \multicolumn{2}{|c|}{ ICSI } \\
\cline { 2 - 3 } & Positive & Negative \\
\hline Extremely low AMH levels $(<0.2 \mathrm{ng} / \mathrm{ml})$ & $3(4.8 \%)$ & $8(12.7 \%)$ \\
\hline Low AMH levels $(0.2-1 \mathrm{ng} / \mathrm{ml})$ & $10(15.9 \%)$ & $42(66.7 \%)$ \\
\hline Total & $13(20.6 \%)$ & $50(79.4 \%)$ \\
\hline$P$-value & 0.123 & \\
\hline Odds ratio & 1.575 & \\
\hline CI Lower & 0.353 & \\
\hline CI Upper & 7.026 & \\
\hline
\end{tabular}

Table (3-8). Comparison between Primary infertility and secondary infertility as regard FSH , LH , LH/FSH ratio and $A M H$ :

\begin{tabular}{|l|c|c|c|}
\hline Parameters & Primary (Mean \pm SD) & Secondary (Mean \pm SD) & P-value \\
\hline FSH (mIU/L) & $10.09 \pm 5.71$ & $9.39 \pm 3.11$ & 0.650 \\
\hline LH (mIU/L) & $5.39 \pm 2.46$ & $5.88 \pm 2.47$ & 0.510 \\
\hline LH/FSH ratio & $0.67 \pm 0.44$ & $0.71 \pm 0.43$ & 0.765 \\
\hline AMH $(\mathrm{ng} / \mathrm{mL})$ & $0.59 \pm 0.37$ & $0.73 \pm 0.34$ & 0.206 \\
\hline
\end{tabular}

\section{DiscuSSION}

AMH has become a prominent tool for the evaluation of ovarian reserve. Recent studies have shown a strong correlation between AMH levels and pregnancy rates $(21,4,22-24)$ where it is expected that the lower the AMH level, the lower the pregnancy rate.

Our study aimed to measure the pregnancy rate in women with low AMH levels $(<1.3 \mathrm{ng} / \mathrm{ml})$ who underwent IVF/ICSI treatment.

In this study 63 women underwent IVF/ICSI in assisted reproductive technology center of Dr.Elsir AbuElhassan.

The study shows that there is a chance to get pregnancy (success ICSI) in women with low serum AMH levels (< $1.3 \mathrm{ng} / \mathrm{ml}$ ), there were 13 women $(20.6 \%)$ gave success ICSI whereas 50 women $(79.4 \%)$ did not get pregnancy (not success ICSI). In agreement with our results Weghofer et al. reported in a large retrospective study, reasonable pregnancy and live birth rates in women with AMH levels ranging from 0.1-0.4 ng/ml (25). By contrast, Nelson and colleagues could not establish any pregnancies in 26 women up to 44 years of age with AMH concentrations $<0.15 \mathrm{ng} / \mathrm{ml}$ using a range of different treatment approaches (4).

More recently, the accuracy of AMH in predicting live birth was tested by independent groups: some data showed that AMH could be used as a prognostic factor $(26,21,27)$ but its predictive value at low or very low concentrations was not clearly clarified.

On the other hand our study examined the difference in IVF outcome in women with low $(<1,3 \mathrm{ng} / \mathrm{ml})$ and extremely low $(<0.2 \mathrm{ng} / \mathrm{ml}$ ) AMH levels, the women were divided into two groups according to their AMH levels including women with extremely low AMH levels $(<0.2 \mathrm{ng} / \mathrm{ml})$ and women with low AMH levels $(0.2-1$ $\mathrm{ng} / \mathrm{ml}$ ). According to our statistical analysis (odds ratio $>1$ ) we found that there was low probability to get 
Success Rate of Intra Cytoplasm Sperm Injection (ICSI) among Sudanese Women with Low Serum Anti-mullerian Hormone (AMH)

pregnancy (success ICSI) in women with extremely low AMH than women with low AMH , 3 women (4.8\%) have extremely low AMH and gave success ICSI whereas 10women (15.9\%)have low AMH and gave success ICSI, the explanation that there was a lower number of oocytes retrieved, a lower number of fertilized oocytes and a lower number of transferred embryos in cycle of women with extremely low AMH levels.

In similar to our result La Marca et al. (2010) found that, for women with very low AMH concentrations(5), either cycle termination or poor response could be anticipated, also Muttukrishna et al. (2004) found that women with very low AMH concentrations are at very high risk for cycle termination(28), and La Marca et al. (2010) proposed that these patients should be refused treatment(5).

Some authors reported acceptable results in terms of clinical pregnancies even in patients with very low AMH levels whereas others suggested their exclusion from IVF treatment due to a very poor prognosis $(17,25)$.

On contrary to our results, other studies showed no significant effect of low AMH level on pregnancy rate and discouraged using AMH level as an indicator for ongoing pregnancy or as prerequisite for infertility treatment $(29,30)$.

This work also shows that there was a significant difference between women gave success ICSI and women gave not success ICSI as regard to serum FSH(p0.023), the explanation that the women with low AMH levels and having high serum FSH results in giving not success ICSI due to poor ovarian response or ovarian failure.

Other studies were documented that higher FSH level was found to be correlated to low AMH level in women expected to have a poor ovarian response $(31,20,32,33)$.

\section{CONCLUSION}

Our data indicate, AMH remains a good quantitative marker of the ovarian reserve but is a poor qualitative marker, it is one of the best available tools for the detection of low ovarian reserve and its role as a clinical test is clear. However, it also appears that reducing the AMH cut-off level below $1.3 \mathrm{ng} / \mathrm{ml}$ by itself does not improve the predictive capacity of pregnancy occurrence following IVF. Therefore, extremely low cut-off AMH values should not be used to exclude couples from IVF treatment.

\section{REFERENCES}

1. Nikolaou D. How old are your eggs? Curr Opin Obstet Gynecol 2008;20:540-4.

2. Fiçicioglu C, Kutlu T, Baglam E, Bakacak Z, Early follicular antimüllerian hormone as an indicator of ovarian reserve. Fertil Steril. 2006 Mar;85(3):592-6.

3. McIlveen M, Skull JD, Ledger WL, Evaluation of the utility of multiple endocrine and ultrasound measures of ovarian reserve in the prediction of cycle cancellation in a high-risk IVF population. Hum Reprod. 2007 Mar;22(3):778-85.

4. Nelson SM, Yates RW, Lyall H, Jamieson M, Traynor I, Gaudoin M, Mitchell P, et al., Anti-Mullerian hormonebased approach to controlled ovarian stimulation for assisted conception. Hum Reprod. 2009 Apr;24(4):867-75.

5. La Marca A1, Sighinolfi G, Radi D, Argento C, Baraldi E, Artenisio AC, Stabile G, Volpe A. Antimullerian hormone (AMH) as a predictor marker in assisted reproductive technology (ART) Hum Reprod Update. 2010;16:113-130.

6. Garcia- Velaso JA, Moreno L, Pacheco A, et al. The aromatase inhibitor letrozole increases the concentration of intraovarian androgens and improves IVF outcome in low responder patients: a pilot study. Fertil Steril. 2005;84:82-87.

American Research Journal of Gynaecology

Page 6 
Success Rate of Intra Cytoplasm Sperm Injection (ICSI) among Sudanese Women with Low Serum Anti-mullerian Hormone (AMH)

7. Grossman MP, Nakajima ST, Fallat ME, Siow Y. Mullerian inhibiting substance inhibits cytochrome P450 aromatase activity in human granulose lutein cell culture. Fertil Steril. 2008;89(Suppl):1364-1370.

8. Durlinger AL, Grujiters MJ, Kramer p, et al. AMH attenuates the effects of FSH on follicle development in the mouse ovary. Endocrinology. 2001;142:4891-4899.

9. Fanchin R, Bouyer J. High reproducibility of serum AMH measurements suggests a multi-staged follicular secretion and strengthens its role in the assessment of ovarian follicular status. Hum Reprod.2005;20:923-927.

10. Hekenkamp WJ, Cw L, Themmen AP, De long FH, Velde T, Broekmans FJ. AMH levels in spontaneous menstrual cycle do not show substantial fluctuation. J Clin Endocrinol Metab. 2006;91:4057-4063. doi: $10.1210 /$ jc.2006-0331.

11. Marca L, Stabile G, Arlenisco AC, Volpe A. Serum AMH throughout the human menstrual cycle. Hum Reprod. 2006;21:3103-3107.

12. Tsepelidis S, Devreker F, Demeestere I, Flahaut A, Gervy C, Englert Y. Stable serum levels of AMH during the menstrual cycle: a prospective study in normo-ovulatory women. Hum Reprod. 2007;22:1837-1840.

13. Van Disseldrop J, Lambalk CB, Kwee J, et al. Comparison of inter and intracycle variability of AMH and antral follicle counts. Hum Reprod. 2010;25:221-22.

14. Visser JA, de Jong FH, Laven JS, Themmen AP. Anti - Müllerian hormone: a new marker for ovarian function. Reproduction. 2006 Jan;131(1):1-9.

15. Koshy AK, Gudi A, Shah A, Bhide P, Timms P, Homburg R. Pregnancy prognosis in women with anti-müllerian hormone below the tenth percentile. Gynecol Endocrinol. 2013;29:662-5.

16. Merhi Z, Zapantis A, Berger DS, Jindal SK. Determining an anti-mullerian hormone cutoff level to predict clinical pregnancy following in vitro fertilization in women with severely diminished ovarian reserve. J Assist Reprod Genet. 2013;30:1361-5.

17. Tocci A, Ferrero S, Iacobelli M, Greco E. Negligible serum anti-mullerian hormone: pregnancy and birth after a 1-month course of an oral contraceptive, ovarian hyperstimulation, and intracytoplasmic sperm injection. Fertil Steril. 2009;92:395 e399-395 e312.

18. Weghofer A, Dietrich W, Barad DH, Gleicher N. Live birth chances in women with extremely low-serum antimullerian hormone levels. Hum Reprod. 2011;26:1905-9.

19. Fraisse T, Ibecheole V, Streuli I, Bischof P, de Ziegler D. Undetectable serum anti-müllerian hormone levels and occurrence of ongoing pregnancy. Fertil Steril. 2008;89:723 e729-711.

20. Tokura Y, Yoshino O, Ogura-Nose S, Motoyama H, Harada M, Osuga Y, et al. The significance of serum antimüllerian hormone (AMH) levels in patients over age 40 in first IVF treatment. J Assist Reprod Genet. 2013;30:821-5.

21. Brodin T, Hadziosmanovic N, Berglund L, Olovsson M, Holte J () Antimullerian hormone levels are strongly associated with live-birth rates after assisted reproduction. J Clin Endocrinol Metab. 2013;98: 1107-1114.

22. Lee TH, Liu CH, Huang CC, Hsieh KC, Lin PM, Lee MS. Impact of female age and male infertility on ovarian reserve markers to predict the outcome of assisted reproduction technology cycles. Reprod Biol Endocrinol. 2009 Sep 17;7:100. 
Success Rate of Intra Cytoplasm Sperm Injection (ICSI) among Sudanese Women with Low Serum Anti-mullerian Hormone (AMH)

23. Nelson SM, Yates RW, Fleming R. Serum anti-Mullerian hormone and FSH: prediction of live birth and extremes of response in stimulated cycles implications for individualization of therapy. Hum Reprod. 2007;22: 2414-2421.

24. Wang JG, Douglas NC, Nakhuda GS, Choi JM, Park SJ, et al. (2010) The association between anti-Mullerian hormone and IVF pregnancy outcomes is influenced by age. Reprod Biomed Online 21: 757-761.

25. Weghofer A, Dietrich W, Barad DH, Gleicher N () Live birth chances in women with extremely low-serum anti-Mullerian hormone levels. Hum Reprod. 2011;26: 1905-1909.

26. Gleicher N, Weghofer A, Barad DH. Anti-müllerian hormone (AMH) defines, independent of age, low versus good live-birth chances in women with severely diminished ovarian reserve. Fertil Steril. 2010;94:2824-7.

27. Iliodromiti S, Kelsey TW, Wu O, Anderson RA, Nelson SM. The predictive accuracy of anti-müllerian hormone for live birth after assisted conception: a systematic review and meta-analysis of the literature. Hum Reprod Update. 2014;20:560-70.

28. Muttukrishna, S., Suharjono, H., McGarrigle, H., Sathanandan, M.,. Inhibin B and anti-Mullerian hormone: markers of ovarian response in IVF/ICSI patients? BJOG 2004;111:1248-1253.

29. Lukaszuk K, Kunicki M, Liss J, Bednarowska A, Jakiel G. Probability of live birth in women with extremely low anti-Müllerian hormone concentrations. Reprod Biomed Online. 2014 Jan;28(1):64-9.

30. Kedem A, Haas J, Geva LL, Yerushalmi G, Gilboa Y, Kanety H, Hanochi M, Maman E, Hourvitz A, Ongoing pregnancy rates in women with low and extremely low AMH levels. A multivariate analysis of 769 cycles. PLoS One. 2013 Dec 16;8(12):e81629.

31. Lehmann P, Vélez MP, Saumet J, Lapensée L, Jamal W, Bissonnette F, Phillips S, Kadoch IJ. AntiMüllerian hormone (AMH): a reliable biomarker of oocyte quality in IVF, J Assist Reprod Genet. 2014 Apr;31(4):493-8.

32. Magri F, Schena L, Capelli V, Gaiti M, Zerbini F, Brambilla E, Rotondi M, et al. Anti-Mullerian hormone as a predictor of ovarian reserve in ART protocols: the hidden role of thyroid autoimmunity. Reprod Biol Endocrinol. 2015 Sep 21;13(1):106.

33. Okunola T, Olusegun Ajenifuja K, Morebise Loto O, Salawu A, Omitinde SO. Follicle stimulating hormone and anti-müllerian hormone among fertile and infertile women in Ile-Ife, Nigeria: is there a difference? Int J Fertil Steril. 2017 Apr-Jun;11(1):33-39.

Citation: Malaz Bashir Alemam, Mohammed Ali Rida, AbdElkarim A. Abdrabo, "Success Rate of Intra Cytoplasm Sperm Injection (ICSI) among Sudanese Women with Low Serum Anti-mullerian Hormone (AMH)". American Research Journal of Gynaecology. 2018; 2(1): 1-8.

Copyright (c) 2018 Malaz Bashir Alemam, Mohammed Ali Rida, AbdElkarim A. Abdrabo, This is an open access article distributed under the Creative Commons Attribution License, which permits unrestricted use, distribution, and reproduction in any medium, provided the original work is properly cited. 